\title{
Towards an explanation of copula effects*
}

\author{
Gerhard Jäger \\ Zentrum für Allgemeine Sprachwissenschaft Berlin \\ jaeger@zas.gwz-berlin.de
}

\begin{abstract}
This paper deals with a series of semantic contrasts between the copula be and the preposition as, two functional elements that both head elementary predication structures. It will be argued that the meaning of $a s$ is a type lowering device shifting the meaning of its complement NP from generalized quantifier type to property type (where properties are conceived as relations between individuals and situations), while the copula be induces a type coercion from (partial) situations to (total) possible worlds. Paired with van der Sandt's 1992 theory of presupposition accommodation, these assumptions will account for the observed contrasts between $a s$ and $b e$.
\end{abstract}

\section{Introduction}

From a semanticist's point of view, the preposition as is a more or less redundant lexical item. While other prepositions have a clear idiosyncratic lexical meaning, as usually doesn't express anything beyond the relation of predication. The constructions in (1) illustrate this.

(1) a. As a skeptical person, John expressed doubts

b. We saw John as a soccer player

At some level of abstraction, (1a) contains the predication John is a skeptical person and (1b) John is a soccer player. Since NPs like a skeptical person or a soccer player are usually considered to be predicates at least in one of their readings, as does not make an obvious semantic contribution here.

Under certain analyses, the same can be said about the copula verb $b e$. So the null theory about the semantics of these two lexical items is that-despite their syntactic differences-they are synonymous, both denoting the identity function over properties, i.e. $\lambda P . P .^{\prime}$

Despite these similarities between $a$ and be, complexes of the form "as + NP" show a semantic behavior that is different from copular predicates, i.e. predicates of the form "be + NP". Fernald 2000 , who discusses some of these effects, christened them "copula effects". This terminology suggests that it is the behavior of the copula that requires explanation, while the preposition as behaves regularly. The proposal that I am going to make here justifies this.

We will focus on three effects:

\subsection{Perception reports}

PPs headed by as may appear as embedded predicate in direct perception reports (in the sense of Barwise 1981), while copular predicates are excluded there.

\footnotetext{
* Special thanks go to Yael Sharvit and Werner Wolff for insightful suggestions concerning the semantics of as, and to Reinhard Blutner, Regine Eckardt, Michael Grabski and Ewald Lang for comments on a previous version of this paper.

${ }^{1}$ There are also syntactic arguments to subsume as and be under one category; see for instance Bowers 1993 who treats these lexical items as two instantiations of a functional category "predication".
} 
(2) a. We saw John as a soccer player

b. We saw John $*$ be $/{ }^{*}$ being a soccer player

Two things should be noted here. The deviance of (2b) cannot simply be attributed to syntax, since both naked infinitives and gerunds are generally admitted in the complement of verbs of perception:

(3) a. We saw John walk

b. We saw John walking

As for (2a), it should be noted that it is not just John who is the object of our perception, and who in turn is a soccer player. Rather, the sentence reports the perception of an abstract eventuality that supports the truth of "John is a soccer player". The arguments in favor of this view are parallel to Barwise's 1981 for a analogous semantic analysis of constructions like (3a). Most importantly, the inference from (4a) and (b) to (c) is invalid, but it should be valid if the as-PP were a secondary predicate.

(4) a. We saw John

b. He was a soccer player at this time

c. Thus we saw John as a soccer player

These things taken into account, (2) provides a genuine minimal pair that requires explanation. This contrast was presumably first noticed in Stump 1985. The analysis provided there is unsatisfactory though for several reasons that will be discussed below.

\subsection{Individual guises}

Individuals ought to be consistent. Your car, say, cannot be both expensive and inexpensive at the same time. So (5) is pragmatically deviant.

(5) Your car is expensive, and it is inexpensive

It is possible though to ascribe conflicting properties to one and the same individual if the predication is appropriately qualified:

(6) Compared with Bill's car, your car is expensive, but in comparison to Henry's car, it is inexpensive

Free as-adjuncts are a good way to supply this kind of qualification of a predication.

(7) a. As a toy your car is expensive, but as a car it is inexpensive

b. As a judge John is corrupt, but as a janitor he is not corrupt (after Landman 1989)

c. As an advisor, Gloria is reliable, but as an administrator she is unreliable (after Katz 1994)

All these example are consistent. A possible analysis (that we will not endorse in the end but which is an intuitively enlightening starting point), individuals come in different guises, and they may have different properties under different guises. Under this perspective, free asadjuncts specify the guise of (the referent of) the subject of the main predication. Copular free adjuncts are unable to do so. All the subsequent examples are inconsistent. 
(8) a. Being a toy, your car is expensive, but being a car, it is inexpensive

b. Being a judge, John is corrupt, but being a janitor, he is not corrupt

c. Being an advisor, Gloria is reliable, but being an administrator, she is unreliable

\subsection{Free adjuncts}

Both as and be are licit as heads of free adjuncts in the sense of Stump 1985. This is illustrated in (9).

(9) a. As a semanticist, Mary is a linguist

b. Being a semanticist, Mary is a linguist

Stump noticed that the class of free adjuncts is divided into two subclasses. The crucial contrast is illustrated in $(10)-(13)$, on the one hand, and $(14)-(17)$ on the other (taken from Stump 1985:41):

(10) a. Wearing that new outfit, Bill would fool everyone

b. If he wore that new outfit, Bill would fool everyone

(11) a. Standing on a chair, John can touch the ceiling

b. If he stands on a chair, John can touch the ceiling

(12) a. Taken in the prescribed dosage, it must be very effective

b. If it is taken in the prescribed dosage, it must be very effective

(13) a. In first gear, the truck might reach the top of that hill

b. If it were in first gear, the truck might reach the top of that hill

Here the (b)-sentences are paraphrases of one of the readings of the (a)-sentences. Stump calls the adjuncts in these examples weak. They are to be contrasted with the following ones:

(14) a. Being a master of disguise, Bill would fool everyone

b. If he were a master of disguise, Bill would fool everyone

(15) a. Having unusually long arms, John can touch the ceiling

b. If he has unusually long arms, John can touch the ceiling

(16) a. Containing twice the iron in a pound of calf's liver, it must be very effective

b. If it contains twice the iron in a pound of calf's liver, it must be very effective

(17) a. Weighing only a few tons, the truck might reach the top of that hill

b. If it weighs only a few tons, the truck might reach the top of that hill

Here the (a)-sentences cannot be paraphrased by the (b)-sentences. These adjuncts Stump calls strong. Note though that both weak and strong adjuncts admit a reading that can be paraphrased with the help of since, so (18a) can mean (18b) and (19a) is paraphrasable as (19b). 
(18) a. In first gear, the truck might reach the top of that hill

b. Since it is in first gear, the truck might reach the top of that hill

(19) a. Weighing only a few tons, the truck might reach the top of that hill

b. Since it weighs only a few tons, the truck might reach the top of that hill

The observation that is crucial for our purposes is the fact that be-adjuncts are always strong while $a s$-adjuncts are invariably weak. The next example is again Stump's (op. cit. pp. 86).

(20) a. Being a blonde, Mary might look something like Jane

b. As a blonde, Mary might look something like Jane

c. If she were a blonde, Mary might look something like Jane

(21) a. Being a semanticist, Mary would be a linguist

b. As a semanticist, Mary would be a linguist

c. If she were a semanticist, Mary would be a linguist

(22) a. Being a supervisor, Sam is always strict

b. As a supervisor Sam is always strict

c. If he is a supervisor, Sam is always strict

In all these cases, the (b)-sentence but not the (a)-sentence can be paraphrased as in (c).

These observations conclude the initial survey of the issues that will be addressed in the paper. The plan is as follows. In section 2 we will briefly review Carlson's 1977 treatment of the perception report data. We will propose a modification of his theory that makes crucial use of a situation based ontology. It avoids some shortcomings that Carlson's approach is faced with. In section 3 we will take up the issue of individual guises. We will argue that the effects sketched above arise out of a particular kind of presupposition accommodation and resolution of lexical underspecification. As background theory of presupposition accommodation, we will assume van der Sandt 1992. Section 4 puts the pieces from sections 2 and 3 together and presents a natural explanation of Stump's weak/strong contrasts. In the final section we will summarize our findings and mention some issues for further research. 


\section{Stages and individuals, situations and worlds}

\subsection{Carlson's treatment of perceptual reports}

Carlson 1977 proposes an ontology that is somewhat richer than what is assumed in standard model theoretic semantics. Like most semanticists, he assumes that there are "ordinary" individuals that possibly change their properties but nevertheless keep their identity over time. These run-of-the-mill individuals are called "objects" by Carlson. Next to objects, he assumes a domain of "kinds" as independent entities. Objects and kinds jointly constitute the domain of "individuals". Finally, he considers a domain of "stages", i.e. temporally and locally restricted parts of individuals. For the purposes of our discussion, we can ignore kinds, so we may consider stages to be time slices of objects. Stages and individuals belong to disjoint domains; the connection between them is established by some predefined relation $\mathbf{R}$ that connects a stage to the individual it is a stage of. So the formula " $\mathbf{R}(a, b)$ " is to be read as "stage $a$ is a time slice of object $b "$ ".

The sortal structure of the domain of individuals is inherited by higher order domains. In particular, Carlson distinguishes between properties of individuals and properties of stages. This distinction is reflected by the type structure of natural languages. Some predicates, so-called "Individual Level Predicates" (ILPs) denote properties of individuals, while "Stage Level Predicates" (SLPs) refer to properties of stages. Likewise, second order predicates may select ILPs or SLPS.

In Carlson's system, both types of predicates may occur in predicative constructions. NPs are always classified as ILP, and some APs belong into that class as well. Here are some examples of copular constructions with ILPs.
a. John is a hero
b. John is the referee
c. John is intelligent
d. John is five feet tall

Adjectival SLPs are also admitted in copular constructions, as well as stage level PPs.
a. John is drunk
b. John is naked
c. John is in South America

The distinction between ILPs and SLPs is crucial for Carlson's analysis of perceptual reports. He treats perception as a relation between stages rather than between individuals. So the sentence

(25) Sally saw Harry

expresses the fact that there are stages $\mathbf{s}$ of the individual Sally and $\mathbf{h}$ of the individual Harry such that $\mathbf{s}$ is in the seeing-relation to $\mathbf{h}$. Since the names Sally and Harry are individual denoting terms though, the lexical entry for the verb see has to be adapted accordingly. Somewhat simplified (because we ignore the Montagovian lifting of objects to quantifiers), it will come out as in (26), where superscripts on the variables indicate their sort. 
(26) $\lambda x^{i} \lambda y^{i} . \exists z^{s} \exists w^{s}\left(\mathbf{R}\left(z^{s}, x^{i}\right) \wedge \mathbf{R}\left(w^{s}, y^{i}\right) \wedge \operatorname{SEE}\left(z^{s}, w^{s}\right)\right)$

Here see is a simple transitive verb. Infinitive embedding see is treated similar. A sentence like (27) Sally saw Harry walk

will receive a similar analysis, with the single complication that the infinite VP is interpreted as a property of the perceived entity. So its semantic representation is

$$
\text { (28) } \exists x^{s} \exists y^{s}\left(\mathbf{R}\left(x^{s}, \mathrm{~s}\right) \wedge \mathbf{R}\left(y^{s}, \mathrm{H}\right) \wedge \operatorname{SEE}\left(x^{s}, y^{s}\right) \wedge \operatorname{WALK}\left(y^{s}\right)\right)
$$

Accordingly, the lexical semantics of infinitive embedding see is

$$
\text { (29) } \lambda x^{i} \lambda P^{s} \lambda y^{i} . \exists z^{s} \exists w^{s}\left(\mathbf{R}\left(z^{s}, x^{i}\right) \wedge \mathbf{R}\left(w^{s}, y^{i}\right) \wedge \operatorname{SEE}\left(z^{s}, w^{s}\right) \wedge P\left(z^{s}\right)\right)
$$

Note that the infinite VP is predicated over the perceived entity, i.e. a stage. Thus only SLPS are licit here. Hence the complement of perceptual reports is a key diagnostic to distinguish SLPs from ILPs.

As Carlson 1977 points out, this diagnostic indicates that all copular predicates are ILP, no matter whether the predicative phrase is SLP or ILP (the examples are mine).
a. *Gulia saw Gulio be a hero
b. *Gulia saw Gulio be the referee
c. *Gulia saw Gulio be intelligent
d. *Gulia saw Gulio be five feet tall
e. *Gulia saw Gulio be drunk
f. *Gulia saw Gulio be naked
g. ${ }^{*}$ Gulia saw Gulio be in South America

The consequences of this observation for Carlson's system are these:

- There are two homonymous copulas, ${ }^{2}$ one embedding ILPs and the other one SLPs, but

- the result of composing either copula with its complement is an ILP.

The ILP embedding copula does not make any semantic contribution, so it can be considered the identity function over individual level properties (even though Carlson treats it syncategorematically). It is given in (31a). The other copula performs a sortal shift from an SLP to an ILP. Its semantics is given in (31b).

$$
\begin{aligned}
& \text { a. } \lambda P^{i} \cdot P^{i} \\
& \text { b. } \lambda P^{s} \lambda x^{i} \cdot \exists y^{s}\left(\mathbf{R}\left(y^{s}, x^{i}\right) \wedge P^{s}\left(y^{s}\right)\right)
\end{aligned}
$$

If we accept perceptual reports as diagnostic, the preposition as is the exact converse of the second version of the copula. Since it is subcategorized for type NP, its complement is always ILP. The resulting PP, however, is generally SLP.

\footnotetext{
${ }^{2}$ In addition to "active $b e$ " and be in passive constructions, that will be ignored throughout this paper.
} 

a. Gulia saw Gulio as a hero
b. Gulia saw Gulio as the referee

So within Carlson's overall framework, the obvious candidate for the lexical semantics of as is Stump's (33):

$$
\lambda P^{i} \lambda x^{s} \cdot \exists y^{i}\left(\mathbf{R}\left(x^{s}, y^{i}\right) \wedge P^{i}\left(y^{i}\right)\right)
$$

Carlson's general approach has been criticized by several authors, mainly for certain shortcomings concerning its treatment of genericity. These issues are of minor importance here; the interested reader is referred to Krifaky et al. 1995 for a detailed discussion. However, the approach to the semantics of perceptual verbs is not completely satisfactory either. The idea of treating the infinite VP in naked infinitive construction as a secondary predicate of the perceived object has been criticized by Barwise 1981 in general, and his arguments apply here too. This can be illustrated by a scenario that Davidson used in a different context (Davidson 1969). Imagine a metal sphere rotating and simultaneously heating. Suppose you see this sphere and its movement, but the change in temperature has no visible effect. Then the following sentence would be true:

(34) You see the sphere rotate, but you don't see it heat

However, in the described scenario, every rotating stage of the sphere is also a heating stage. So Carlson's semantics would predict the sentence to be false.

There are certain aspects in Carlson's approach though that are intuitively enlightening and deserve to be maintained even though the theory as such needs to be revised. First of all, it is a striking advantage of his theory that it gives a principled explanation of copula effects to start with. Competing theories about the SLP/ILP contrast like Diesing 1992 or Kratzer 1995 predict that the copula has no impact on the classification of a predicate as stage level or individual level. If this were true, copula effects would be entirely mysterious.

Our own proposal will preserve the following features of Carlson's theory:

- The unacceptability of the examples in (30) results from a semantic incompatibility rather than from syntactic constraint violations.

- Objects of perception are partial objects.

- Copular constructions express properties of total objects, while as-PPs denote properties of partial objects.

- Therefore $a s$-phrases, but not be-phrases are acceptable in perceptual reports.

These Carlsonian (and to some degree Stumpian) ideas will be combined with a more recent approach to the semantics of perceptual reports, where objects of perception are assumed to be eventualities rather than individuals.

\subsection{Worlds and situations}

Barwise 1981 and Higginbotham 1983 present thorough examinations of the syntax and semantics of perceptual reports involving naked infinitives. They both come to the conclusion that a sentence like (35a) should be analyzed as a paraphrase of (35b). 

a. John saw Harry walk
b. There is an eventuality $s$ such that Harry walked in $s$ and John saw $s$

The mentioned authors defend different views concerning the ontological nature of the abstract eventuality $s$ that is the object of perception here. While Barwise develops a completely new foundation of semantics, situation theory, Higginbotham identifies $s$ as an event in the sense of Davidson 1967. His ontology is thus entirely classical and extensional.

Both Barwise's situations and Davidson's events are, in a sense, small or partial objects, i.e. they are part of the world and can be localized both locally and temporally. This makes them plausible candidates for objects of perception. Also, they share these properties with Carlson's stages. If we want to maintain Carlson's insight that the ungrammaticality of copular constructions in the complement of verbs of perception is due to a partiality/totality mismatch, we have to look for total counterparts of (partial) situations/events. Possible worlds are obvious candidates. However, neither Barwise's nor Davidson's ontology considers possible worlds as eventualities, total or not. Davidson's ontology is purely extensional, and Barwise assumes that there is only one possible world - the real world -that is too large (in a set theoretic sense) to be a situation. So to carry through our neo-Carlsonian program, we have to work in an ontological framework that maintains the basic ingredients of the Barwise/Higginbotham analysis while allowing co-existence of worlds and situations. Kratzer's 1989 version of situation theory provides a good starting point. Modifying her proposal slightly, our ontology contains the following basic ingredients (cf. Kratzer 1989, pp. 614):

$S \quad$ a set, the set of possible situations

A a set, the set of possible individuals

$\leq$ a partial ordering on $S \cup A$ such that at least the following conditions are satisfied:

(i) For no $s \in S$ is there an $a \in A$ such that $s \leq a$

(ii) For all $s \in S \cup A$ there is a unique $s^{\prime} \in S$ such that $s \leq s^{\prime}$ and for all $s^{\prime \prime} \in S$ : if $s^{\prime} \leq s^{\prime \prime}$, then $s^{\prime \prime}=s^{\prime}$.

$\mathcal{P}(S) \quad$ the power set of $S$, the set of propositions

$W$ a subset of $S$, the set of maximal elements with respect to $\leq . W$ is the set of possible worlds.

A few words of comment are in order. In comparison to other situation theories, Kratzer's is conservative in sticking to a bivalent logic. So a proposition is either true or false in a situation. tertium non datur. This makes Kratzerian situations similar to Davidsonian events; if we chose a metalanguage that contains variables over situations, we may consider situations as additional arguments of predicates in an extensional type theory. Individuals may be parts of situations, and individuals may be parts of other individuals, but a situation cannot be a part of an individual. Possible worlds are a special kind of situations. They are maximal with respect to the part-of structure of the domain of situations, so they cannot be properly extended. All individuals and all situations belong to exactly one possible world. So modal statements involving individuals or situations require a theory of counterparts.

For the purposes of this paper, the role of possible individuals in the ontology, and all issues concerning cross-world identification of individuals and situations may savely be ignored as irrelevant. We do need the dichotomy of worlds and situations, and the conception of propositions as sets of possible situations. 
Kratzer does not discuss the issue of localizability of situations in space and time, but these aspects can easily be accommodated. Staying close to a Davidsonian intuition, we may extend the ontology with

$T$ a set, the set of time intervals that is partially ordered by $\subseteq_{T}$ (inclusion) and $\leq_{T}$ (precedence).

$L \quad$ a subset of $A$, the set of locations

$\tau$ a partial function from $S$ to $T$ (temporal location) such that the domain of $\tau$ is disjoint from $W$ and $\tau(s) \Xi_{T} \tau\left(s^{\prime}\right)$ entails $s \leq s^{\prime}$

$l$ a partial function from $S$ to $L$ (location in space) such that the domain of $l$ is disjoint from $W$

To say it in plain English, situation may, but need not be located in space and time. For certain situations, like those that support the truth of mathematical statements, such a location does not make intuitive sense. Possible worlds are generally considered to be too large to be located either in space or in time.

Temporal location together with the partial order $\leq$ on situations induce a derived partial order:

$$
s \sqsubseteq s^{\prime} \text { iff } \tau(s)=\tau\left(s^{\prime}\right) \text { and } s \leq s^{\prime}
$$

This ordering relates those situations that take place in the same world at the same time. We postulate that for any $s$ in the domain of $\tau$, there is a unique $s^{\prime}$ such that $s \sqsubseteq s^{\prime}$ and for all $s^{\prime \prime}$, if $s^{\prime} \sqsubseteq s^{\prime \prime}$ then $s^{\prime}=s^{\prime \prime}$. Thus we define the domain

$W T$ the set of world-time slices, the set of maximal elements with respect to $\sqsubseteq$

$W S \quad$ the set of world size situations, i.e. the set $\left\{w \mid \exists w^{\prime} \in W T: w^{\prime} \leq w\right\}$

Note that the world-time slices are big insofar as they contain everything that is the case in their world in a given interval of time, but they are small insofar as they are in the domain of $\tau$. Still, they are too big to be in the domain of $l$, and-central for our purposes- they are too big to be objects of perception. World size situations are at least as big as world time slices, so they are generally too big for perception too.

With this ontological background, we are ready to formulate the neo-Carlsonian premises of our approach to the semantics of perception reports:

- Perception is a relation between an individual and a small situation, i.e. a situation that is in the domain of both $l$ and $\tau$

- Copular constructions express propositions that are true only in big situations, i.e. in world size situations.

- The propositions expressed by small clauses headed by as may be true in small situations.

It is imperative to admit that (the propositions expressed by) copular constructions may be true in world-time slices and not just in worlds, since copular constructions are compatible with frequency adverbials:

a. John was a referee several times 
b. Harry is the chairperson again

On the other hand, Maienborn $1999 \mathrm{~b}$ points out that copular constructions are incompatible with situation external locative modifiers.
a. *Mary was tired in the car last night
b. *Paul is hungry over there

This observation is accounted for by the assumption that world-time slices are too big to be localized in space.

As a first step towards a compositional development, the be-predicate be a soccer fan and the $\mathrm{PP}$ as a soccer fan should be interpreted roughly as follows:
a. be a soccer fan $\Rightarrow \lambda x \lambda w . w \in W S \wedge x$ is a soccer fan in $w$
b. as a soccer fan $\Rightarrow \lambda x \lambda s . x$ is a soccer fan in $s$

Next it has to be decided which predicate is more basic. In other words, the predicative NP $a$ soccer fan certainly supplies an eventuality argument (that originates from the property soccer fan, which is a relation between individuals and eventualities, like every property). The question is whether or not the eventuality argument of the NP ranges over elements of $W S$. In the first case, as would somehow neutralize this sortal information; otherwise be has to be assumed to supply it. We opt for the second version, for two reasons. First, meaning composition is most naturally viewed as a monotonic process where information is composed and not destroyed. Only the second variant follows this strategy. Second, in the situation semantic literature it is commonly assumed that every NP comes with its own situation which might be different both from the described situation and the utterance situation (cf. for instance the discussion in Gawron and Peters 1990 or, in a Kratzerian framework, von Fintel 1994). That this assumption is virtually conceptually necessary can be seen from examples with deictic NPs, as in

(39) This house is larger than this house

For this sentence to make sense, the referential situations for the subject and the object must be different. They are part of the same world though. Granting every NP its own situation argument is thus independently motivated.

Given this, the semantic contribution of as is twofold. First it performs a type lowering from the generalized quantifier type of its NP argument to the type property of the entire PP. Second it makes the situation argument of the complement NP - which we assume to be existentially bound by default-syntactically accessible.

The latter operation is known as "existential disclosure" in the literature (Dekker 1990). It is only definable in a dynamic framework. We chose a compositional version of Discourse Representation Theory (Kamp 1981; Kamp and Reyle 1993), following suggestions developed in Asher 1993 and Zeevat 1989. ${ }^{3}$ There the NP a soccer fan will receive the translation ${ }^{4}$

\footnotetext{
${ }^{3}$ The recursive model theoretic interpretation is given in the appendix.

${ }^{4}$ We use a linear notation mainly for typographic reasons. The translation into to customary box notation should be obvious; the following structure would come out as $\lambda P \lambda s, \begin{aligned} & \frac{x, s^{\prime}}{\operatorname{SOCCERFAN}\left(s^{\prime}, x\right)} \\ & P(s, x)\end{aligned}$
} 
(40) $\lambda P \lambda s \cdot\left[x, s^{\prime} \mid \operatorname{SOCCERFAN}\left(s^{\prime}, x\right), P(s, x)\right]$

So the lexical meaning of as comes out as (41a), which combines with a soccer fan to an expression that is equivalent to (41b).
a. as $\Rightarrow \lambda T \lambda y \lambda s^{\prime \prime} \cdot T\left(s, \lambda z \lambda s^{\prime \prime \prime} \cdot\left[\mid z=y, s^{\prime \prime}=s^{\prime}\right]\right)$
b. as a soccer fan $\Rightarrow \lambda x \lambda s$. [| $\operatorname{socCERFAN}(s, x)]$

As for the copula, we follow Partee 1986 in the assumption that be always applies to a property. NP predicatives are lowered from generalized quantifier type to property type by means of a phonetically empty type shifting operator $i d$. The semantics of $i d$ is identical to the semantics of as given above. The copula itself only performs a sortal shift from unrestricted situations to world size situations. So its lexical semantics is
a. be $\Rightarrow \lambda P \lambda x \lambda w \cdot[s \mid P(s, x), w \in W S, s \sqsubseteq w]$
b. be a soccer fan $\Rightarrow \lambda x \lambda w \cdot[s \mid \operatorname{soccerfaN}(s, x), w \in W S, s$ [ $w]$

Note the similarity between this proposal for the semantics of the copula and Carlson's SLP embedding copula. The main difference is the fact that now the eventuality argument rather than the subject argument is shifted from a partial to a total sort.

The final piece that is to be supplied is the semantics of perceptual verbs like see. As mentioned above, objects of perception are small situations, i.e. they must not be members of $W S$. So we arrive at the lexical entry

$$
\text { see } \Rightarrow \lambda P \lambda T \lambda x \lambda s \cdot\left[s^{\prime} \mid T\left(s^{\prime}, P\right), s^{\prime} \not W S, \operatorname{SEE}\left(s, x, s^{\prime}\right)\right]
$$

After a series of $\lambda$-conversions and simplifications, we arrive at the following DRSs for the minimal pair John saw Harry $\{$ as/be $\}$ a soccer fan:

$$
\begin{aligned}
& \text { a. John saw Harry as a soccer fan } \Rightarrow \\
& {\left[x, y, s, s^{\prime} \mid \operatorname{JOHN}(x), \operatorname{HARRY}(y), \operatorname{SOCCERFAN}(s, y), s \neq W S, \operatorname{SEE}\left(s^{\prime}, x, s\right)\right]} \\
& \text { b. John saw Harry be a soccer fan } \Rightarrow \\
& {\left[x, y, s, s^{\prime}, w \mid \operatorname{JOHN}(x), \operatorname{HaRRY}(y), \operatorname{SOCCERFAN}(s, y), w \notin W S, w \in W S, s \sqsubseteq w,\right.} \\
& \left.\quad \operatorname{SeE}\left(s^{\prime}, x, w\right)\right]
\end{aligned}
$$

Obviously a copular predicate in a perceptual report results in a contradiction since the perceived situation is required to be big and small simultaneously. This results in unacceptability. ${ }^{5}$

Let us summarize the explanation of the copula effects in perceptual reports that was developed in this section. The key assumptions are the following:

- We adopt a slightly modified Kratzer style situation theory.

- We distinguish between big (i.e. world size) and small (i.e. localizable) situations. Only small situations can be perceived.

\footnotetext{
${ }^{5}$ Later we will incorporate presuppositions and treat these contradictory requirements as conflicting presuppositions. This will result in outright uninterpretability.
} 
- Following Barwise and Higginbotham, we analyse perceptual reports as expressing a relation between the perceiver and a perceived situation that is in turn described by the complement of the verb.

- NP predicatives supply a situation argument of unspecified size.

- The preposition as leaves the size of the situation argument unspecified, so the result is consistent with the requirement of the matrix verb that the perceived situation be small.

- The copula be absorbs the situation argument from the predicative and instead returns a world size eventuality argument. This results in a conflict with the requirements imposed by the matrix verb.

\section{Guises vs. presuppositions}

\subsection{Landman 1989}

The best known approach to the semantics of as-headed adjuncts is given in Landman 1989. There only adnominal as-PP are considered. According to our (and Fox's 1993) intuitions, adnominal $a s$-adjuncts modifying the subject are synonymous to the corresponding adverbial constructions. In other words, we consider the following two sentences synonymous.
a. John as a judge is corrupt
b. As a judge, John is corrupt

We thus restrict our attention to the adverbial use of $a s$-PPs.

Landman gives eight axioms that a correct analysis of as has to validate.

1. John as a judge is still John

2. John as a judge is a judge

3. John as John is John

4. If John as a judge is corrupt and John as a judge is well paid then John as a judge is corrupt and well paid.

5. If John as a judge takes bribes and taking bribes implies being corrupt, then John as a judge is corrupt

6. It is not the case that John as a judge both is and is not corrupt

7. John as a judge either takes or doesn't take bribes

8. If John as a judge is corrupt, John is a judge

These axioms sound innocuous, and as they stand, they are consistent. They are intended as axiom schemes, however. If you replace John by any other name or being a judge, being corrupt, taking bribes etc. by any other predicate, the results should still be axioms. Now consider axioms 1 and 8. Replacing being corrupt in 8 by being John, we arrive at 
8a. If John as a judge is John, John is a judge

The left hand side of this conditional is identical with axiom 1, so we may apply Modus Ponens and derive the conclusion

\section{$8 b$. John is a judge}

If we replace the predicate judge in $8 \mathrm{a}$. by non-judge, we may employ the same line of argument to infer that John is a non-judge. In other words, Landman's axiom schemes imply that John (and any other individual) has all properties; they are inconsistent. ${ }^{6}$

Still, these axioms sound plausible, so we should ask which minimal adjustments have to be made to render them consistent. I think that the only problematic aspect is the status of axiom 8. Landman presents this inference as an ordinary implication. Instead, I follow Umbach 1996 to interpret it as a presupposition. So axiom 8 should be strengthened to

\section{8'. "John as a judge is corrupt" presupposes that John is a judge}

Given this, the axioms 1,2, and $4-7$ have a tautological assertoric part, but according to the laws of presupposition projection, they all have a non-trivial presupposition, namely that John is a judge. So it is no surprise that we may infer from axiom 1 that John is a judge. To transform axioms 1,2, and 4-7 into ordinary tautologies, we have to prefix them each with "If John is a judge ...".

It goes without saying that under this perspective, an adequate account of the semantics of asheaded adjuncts requires a theory of presuppositions. We will make use of van der Sandt's approach that will briefly be introduced in the next subsection.

\subsection{Presuppositions in DRT: van der Sandt 1992}

In his seminal article van der Sandt 1992, Rob van der Sandt proposes a unification of the seemingly unrelated phenomena of anaphora and presupposition. He uses Kamp's Discourse Representation Theory as background theory. The treatment of anaphora in this framework is well-understood. Taking this as a starting point, he extends DRT with presuppositions. Presuppositions are treated as a kind of complex anaphors, and binding of presuppositions is completely analogous to anaphora binding. However, presuppositions admit a last resort resolution strategy that is applicable if binding fails, namely accommodation. Van der Sandt demonstrates that presupposition accommodation can be incorporated into his DRT-framework in a natural way. So perspectives might be switched; in this theory, anaphors are a special kind of presupposition that are special only because they do not accommodate.

Rather than going through the formal details of van der Sandt's theory, we will illustrate how it works with a few key examples. Before we do that, some words about the meta-theoretical status of presuppositions are in order though. Up to now, we have treated DRT as something analogous to Intensional Logic in Montague Grammar, i.e. a convenient level of representation that can in principle be dispensed with, thus being compatible with a strategy of direct compositional interpretation. This is at odds with van der Sandt's intentions, since there DRSs are a crucial syntactic level of representation that is indispensable for the treatment of presuppositions. Only complete DRSs without unresolved presuppositions can be interpreted.

\footnotetext{
${ }^{6}$ This was first pointed out in Fox 1993.
} 
Since the issue of compositionality is orthogonal to the problems discussed in this paper, we will not go any further into this problem. Disciples of orthodox DRT may view the use of $\lambda$-conversion as a cumbersome DRS construction algorithm without semantic impact. For adherents of direct interpretation it should be added as a reassurance that Zeevat 1992 gives a compositional reformulation of van der Sandt's theory. Combining this with $\lambda$-abstraction would be a tedious but not overly difficult technical exercise. We leave this for another occasion.

Having said this, we can start with practical work. While in standard DRT a DRS consists of two components - the discourse markers and the DRS conditions-in van der Sandt's extension they have a third component, their anaphoric part. Technically speaking this is a (possibly empty) set of DRSs. So the translation of (46a), a sentence without any presupposition triggers, is (46b). We adopt the convention of separating the DRS conditions from the anaphoric part with a slash. If the anaphoric part is empty, we will omit it, so the abbreviated representation of (a) is (c).
a. A man entered
b. $[x \mid \operatorname{MAN}(x), \operatorname{ENTER}(x) / \emptyset]$
c. $[x \mid \operatorname{MAN}(x), \operatorname{ENTER}(x)]$

Next we consider a case of presupposition binding. Let us assume that a definite description induces an existence presupposition, but no uniqueness presupposition. Then the discourse in (47a) will receive the initial representation (47b).
a. A man entered. The man whistled.
b. $[x \mid \operatorname{MAN}(x), \operatorname{EnTER}(x), \operatorname{Whistle}(y) /\{[y \mid \operatorname{Man}(y)]\}]$

Binding a presupposition consists of three steps. First you have to find a mapping from the discourse referents in the universe of the presupposed DRS to discourse referents that are accessible from the position of this presupposed DRS. Second you have to replace every discourse referent in the conditions of the presupposed DRS by its image under this mapping. Finally you have to check whether the resulting DRS-conditions are subsumed by the embedding DRS. ${ }^{7}$

In the example, mapping $y$ to $x$ would fulfill this requirement since the presupposed condition $\operatorname{MAN}(y)$ is transformed to MAN $(x)$ under this mapping, and this condition is part of the embedding context. All occurrences of the presupposed discourse marker are replaced by their image under this mapping. So presupposition binding is a transformation on DRSs that would transform $(47 b)$ to $(48)$.

$$
[x \mid \operatorname{Man}(x), \operatorname{ENTER}(x), \operatorname{WhistLe}(x)]
$$

Note that this operation (as well as accommodation) is only defined if the anaphoric part of the presupposition is empty. So if a presupposition embeds another presupposition, resolution has to work inside out, starting with the most deeply embedded presupposition. An example is (49a). Its initial representation is (49b), which is transformed first to (c) and finally to (d).

$$
\begin{aligned}
& \text { a. If a man is blond, Mary will realize that the man is blond. } \\
& \text { b. }[x \mid \operatorname{MARY}(x),[y \mid \operatorname{MAN}(y), \operatorname{BLOND}(y)] \Rightarrow \\
& [\mid \operatorname{REALIZE}(x,[\mid \operatorname{BLOND}(z) /\{[z \mid \operatorname{MAN}(z)]\}]) /\{[\mid \operatorname{BLOND}(w) /\{[w \mid \operatorname{MAN}(w)]\}]\}]]
\end{aligned}
$$

\footnotetext{
${ }^{7}$ The last condition is missing in van der Sandt's paper, but leaving it out leads to massively inadequate results.
} 

c. $[x \mid \operatorname{MaRY}(x),[y \mid \operatorname{MAN}(y), \operatorname{BLOND}(y)] \Rightarrow$ $[\mid \operatorname{ReALiZE}(x,[\mid \operatorname{BLOND}(y)]) /\{[\mid \operatorname{BLOND}(y)]\}]]$
d. $[x \mid \operatorname{Mary}(x),[y \mid \operatorname{MAN}(y), \operatorname{BLOND}(y)] \Rightarrow[\mid \operatorname{ReAlize}(x,[\mid \operatorname{BLOND}(y)])]]$

Pronominal anaphors are analyzed as degenerate presuppositions that consist only of a discourse marker (plus, possibly, some sortal information about number and gender). So the classical (50a) will be represented as $(50 \mathrm{~b})$, which, after binding, becomes $(50 \mathrm{c})$.
a. A man walks. He whistles
b. $[x \mid \operatorname{MAN}(x), \operatorname{WALK}(x), \operatorname{WHISTLE}(y) /\{[y \mid]\}]$
c. $[x \mid \operatorname{Man}(x), \operatorname{WALK}(x), \operatorname{WHISTLE}(x)]$

Van der Sandt assumes that there is a preference for "deep" binding, i.e. if there are several potential binders at different levels of embedding around for a presupposed discourse marker, binding on a deeper level of embedding will be preferred. So in (51), the system (correctly) predicts that binding $i t$ to the second occurrence of $a d o g$ is the preferred reading.

(51) There is a dog, and if Fido sees a dog, he attacks it.

In many cases, a presupposition does not find an appropriate binder. Presupposition accommodation is a repair strategy that renders such a discourse interpretable. In the present system, the implementation of this idea is extremely simple: we simply add the presupposition to some DRS that is accessible from the original site of the presupposition. Adding a DRS $K$ to a DRS $K^{\prime}$ is defined component-wise: Add the discourse referents of $K$ to the universe of $K^{\prime}$ and the DRS conditions of $K$ to the conditions of $K^{\prime}$. The anaphoric part of $K$ must be empty for accommodation to be defined. Since in the general case, there may be several potential accommodation sites accessible for a presupposition, this process is non-deterministic. To take a simple example, (52a) receives the initial representation (52b). Since binding is impossible here, accommodation is called for. Each of $(52 \mathrm{c}, \mathrm{d}, \mathrm{e})$ are candidates for the final representation.

(52) a. If Mary becomes a club member, the president will resign

b. $[x \mid \operatorname{MARY}(x),[\mid \operatorname{BECOME}$ Member $(x)] \Rightarrow$ $\left.\left[\mid \operatorname{WILL} \_R E \operatorname{SigN}(y) /\{[y \mid \operatorname{PRESIDENT}(y)]\}\right]\right]$

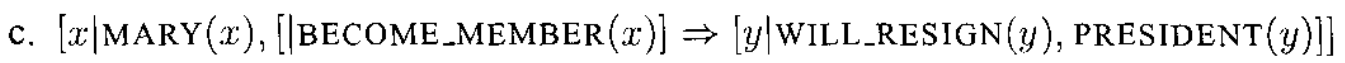

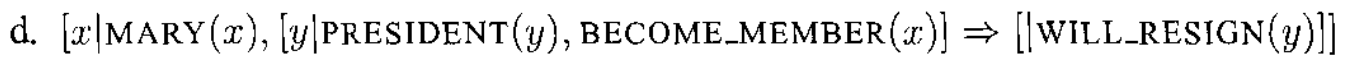

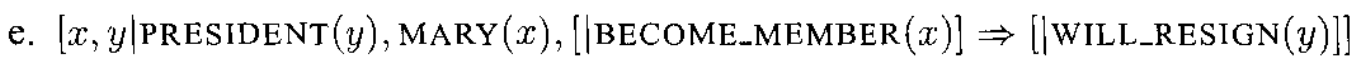

These three options are traditionally called local, intermediate, and global accommodation, respectively. Van der Sandt assumes a preference for "high" accommodation. So in the example, (52d) is correctly predicted to represent the preferred interpretation. However, if a presupposition contains a discourse marker that is bound from outside, accommodation must not lead to unbinding of that discourse marker. The next example illustrates this.

a. If Mary becomes a member of a club, its president will resign

b. $[x \mid \operatorname{MARY}(x),[y \mid \operatorname{CLUB}(y), \operatorname{BECOME}-\operatorname{MemBER}(x, y)] \Rightarrow$ $[\mid$ WILL_RESIGN $(z) /\{[z \mid \operatorname{PRESIDENT}(z, w) /\{[w \mid]\}]\}]]$ 


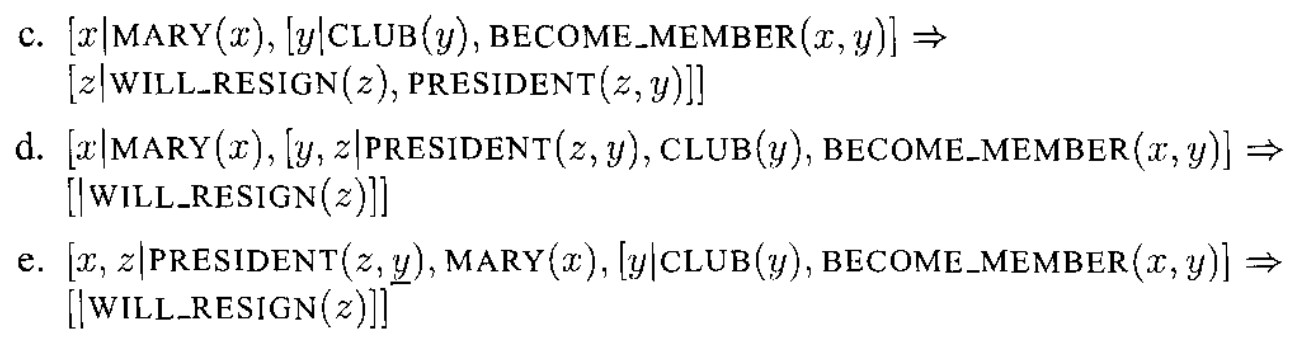

In (53e), i.e. under global accommodation, the underlined occurrence of the discourse marker " $y$ " is not bound. Thus this reading is excluded. Only (c) and (d) are good candidates for accommodation. Since the accommodation site in (d) is higher than in (c), intermediate accommodation wins here.

\section{3. $A s, b e$, and what they presuppose}

After having set the stage, we can start to look at the anaphoric aspects of the adjunct constructions we are interested in. First a pragmatic stipulation: we assume that our discourse representation at the beginning of a discourse is never completely empty. There will always be at least an evaluation index $w_{0}$ which is known to be world sized. More formally, our initial DRS will be at least $\left[w_{0} \mid w_{0} \in W S\right]$. Next, we assume that the information $w \in W S$ that occurs in the lexical entry of the copula in (42a) should be considered a presupposition. Furthermore we stipulate that the situation argument of a sentence is filled with an anaphoric situation anaphor after semantic composition is completed. So the initial representation of (54a) is (54b), which after merging with the default context leads to $(54 \mathrm{c})$ via presupposition resolution.
a. John is a judge
b. $[s, x \mid \operatorname{JOHN}(x), \operatorname{JUdGE}(s, x), s \sqsubseteq w /\{[\mid w \in W S],[w \mid]\}]$
c. $\left[w_{0}, s, x \mid w_{0} \in W S, \operatorname{JOHN}(x), \operatorname{JUdGE}(s, x), s \sqsubseteq w_{0}\right]$

Furthermore we assume that the adjuncts that are discussed in this paper are generally frame setting in the sense of Maienborn 1999a,b. ${ }^{8}$ We adopt two crucial features of Maienborn's analysis here. First, Maienborn assumes that frame setting adjuncts are topical. While a discussion of topic/comment structure lies outside the scope of this paper, it is certainly on a line with Maienborns approach to assume that topical material is old material, i.e. presupposed. Second, Maienborn suggests that the eventuality argument of frame setting adjuncts is freely supplied by pragmatics. Translated into the current framework, this means that the situation argument of these adjuncts is filled by a situation anaphor. Under these assumptions, (55a) is translated as (55b) and thus interpreted either as (55c) or (d). (Since both are logically equivalent under the proviso that JUDGE and CORRUPT are persistent predicates, we do not have to choose between them).
a. John as a judge is corrupt
b. $\left[s, x \mid \operatorname{JOhN}(x), \operatorname{CORRUPT}(s, x), s \sqsubseteq w /\left\{[\mid w \in W S],[w \mid],\left[\mid \operatorname{JUdgE}\left(s^{\prime}, x\right),\left[s^{\prime} \mid\right]\right\}\right]\right]$
c. $\left[w_{0}, s, x \mid w_{0} \in W S, \operatorname{JOHN}(x), \operatorname{CORRUPT}(s, x), s \sqsubseteq w_{0}, \operatorname{JUdGE}(w, x)\right]$

\footnotetext{
${ }^{8}$ This does not exclude the possibility of non-frame setting adverbials headed by as. The following example illustrates that such constructions exist, even though we will ignore them throughout this paper.

(i) John died as a catholic
} 


\section{d. $\left[w_{0}, s, x \mid w_{0} \in W S, \operatorname{JOHN}(x), \operatorname{CORRUPT}(s, x), s \sqsubseteq w_{0}, \operatorname{JUdGE}(s, x)\right]$}

With this background, we can have another look at Landman's axioms. The (a) versions give an English formulation of the respective axiom under the modifications that have been motivated above. The (b) sentences give their underspecified representation, while (c) represents the final interpretation.

(56) a. If John is a judge, John as a judge is John

b. $[x \mid \operatorname{JOHN}(x),[s \mid \operatorname{JUDGE}(s, x), s \sqsubseteq w /\{[\mid w \in W S],[w \mid]\}] \Rightarrow$ $\left.\left[s_{1} \mid \operatorname{JOHN}(x), s_{1} \sqsubseteq w /\left\{[\mid w \in W S],[w \mid],\left[\mid \operatorname{JudGE}\left(s_{2}, x\right),\left[s_{2} \mid\right]\right\}\right]\right]\right]$

c. $\left[w_{0}, x \mid w_{0} \in W S, \operatorname{JOHN}(x),\left[s \mid \operatorname{JUdGE}(s, x), s \sqsubseteq w_{0}\right] \Rightarrow\right.$ $\left.\left[s_{1} \mid \operatorname{JOHN}(x), s_{1} \sqsubseteq w_{0}\right]\right]$

(57) a. If John is a judge, John as a judge is a judge

b. $[x \mid \operatorname{JOHN}(x),[s \mid \operatorname{JUdGE}(s, x), s \sqsubseteq w /\{[\mid w \in W S],[w \mid]\}] \Rightarrow$ $\left.\left[s_{1} \mid \operatorname{Judge}\left(s_{1}, x\right), s_{1} \sqsubseteq w /\left\{[\mid w \in W S],[w \mid],\left[\mid \operatorname{JudgE}\left(s_{2}, x\right),\left[s_{2} \mid\right]\right\}\right]\right]\right]$

c. $\left[w_{0}, x \mid w_{0} \in W S, \operatorname{JOHN}(x),\left[s \mid \operatorname{JUdGE}(s, x), s \sqsubseteq w_{0}\right] \Rightarrow\right.$ $\left.\left[s_{1} \mid \operatorname{JUDGE}\left(s_{1}, x\right), s_{1} \sqsubseteq w_{0}\right]\right]$

(58) a. John as John is John

b. $\left[s, x \mid \operatorname{JOHN}(x), s \sqsubseteq w /\left\{[\mid w \in W S],[w \mid],\left[\mid \operatorname{JOHN}(x),\left[s^{\prime} \mid\right]\right\}\right]\right]$

c. $\left[w_{0}, s, x \mid w_{0} \in W S, \operatorname{JOHN}(x), s \sqsubseteq w_{0}\right]$

(59) a. If John is a judge, then if John as a judge is corrupt and John as a judge is well paid, John as a judge is corrupt and well paid

b. $\left[x \mid \operatorname{JOHN}(x),\left[s_{1}, s_{2}, s_{4} \mid \operatorname{JUdGE}\left(s_{1}, x\right), s_{1} \sqsubseteq w_{1}, \operatorname{CORRUPT}\left(s_{2}, x\right), s_{2} \sqsubseteq w_{2}\right.\right.$, WELL_PAID $\left(s_{4}, x\right), s_{4} \sqsubseteq w_{3} /\left\{\left[\mid w_{1} \in W S\right],\left[w_{1} \mid\right],\left[\mid w_{2} \in W S\right],\left[w_{2} \mid\right]\right.$, $\left.\left[\mid \operatorname{JudgE}\left(s_{3}, x\right)\right],\left[s_{3} \mid\right],\left[\mid w_{3} \in W S\right],\left[w_{3} \mid\right],\left[\mid \operatorname{JUdgE}\left(s_{5}, x\right),\left[s_{5} \mid\right]\right\}\right] \Rightarrow$ $\left[s_{6} \mid \operatorname{CORRUPT}\left(s_{6}, x\right)\right.$, WELL_PAID $\left(s_{6}, x\right), s_{6} \sqsubseteq w_{4} /$ $\left.\left.\left.\left\{\left[\mid w_{4} \in W S\right],\left[w_{4} \mid\right],\left[\mid \operatorname{JUdGE}\left(s_{7}, x\right),\left[s_{7} \mid\right]\right\}\right]\right]\right]\right]$

c. $\left[w_{0}, x \mid w_{0} \in W S, \operatorname{JOHN}(x)\right.$

$\left[s_{1}, s_{2}, s_{4} \mid \operatorname{JUdGE}\left(s_{1}, x\right), s_{1} \sqsubseteq w_{0}, \operatorname{CORRUPT}\left(s_{2}, x\right), s_{2} \sqsubseteq w_{0}, \operatorname{WELL} \_\operatorname{PaID}\left(s_{4}, x\right)\right.$, $\left.s_{4} \sqsubseteq w_{0}\right] \Rightarrow\left[s_{6} \mid \operatorname{CORRUPT}\left(s_{6}, x\right), \operatorname{WeLL} \_\right.$PaId $\left.\left.\left(s_{6}, x\right), s_{6} \sqsubseteq w_{0}\right]\right]$

(60) a. If John is a judge, John as judge takes bribes, and taking bribes implies being corrupt, then John as a judge is corrupt.

b. $\left[x \mid \operatorname{JOHN}(x),\left[s_{1}, s_{2} \mid \operatorname{JUdGE}\left(s_{1}, x\right), \operatorname{TAKE} \_B R I B E S\left(s_{2}, x\right), s_{1} \sqsubseteq w_{1}, s_{2} \sqsubseteq w_{2}\right.\right.$ $\left[s_{3}, y \mid\right.$ TAKE_BRIBES $\left.\left(s_{3}, y\right)\right] \Rightarrow\left[\mid \operatorname{CORRUPT}\left(s_{3}, y\right)\right] /$

$\left\{\left[\mid w_{1} \in W S\right],\left[\left.w_{1}\right|_{1},\left[\mid w_{2} \in W S\right],\left[w_{2} \mid\right],\left[\mid \operatorname{JUdGE}\left(s_{4}, x\right)\right],\left[s_{4} \mid\right]\right\}\right] \Rightarrow$ $\left[s_{5} \mid \operatorname{CORRUPT}\left(s_{5}, x\right), s_{5} \sqsubseteq w_{3} /\left\{\left[w_{3} \in W S\right],\left[w_{3} \mid\right]\right.\right.$; [ $\left.\left.\left.\left[\operatorname{JUdGE}\left(s_{6}, x\right)\right],\left[s_{6} \mid\right]\right\}\right]\right]$

c. $\left[w_{0}, x \mid w_{0} \in W S, \operatorname{JOHN}(x),\left[s_{1}, s_{2} \mid \operatorname{JUdGE}\left(s_{1}, x\right), \operatorname{TAKE} \_B R I B E S\left(s_{2}, x\right), s_{1} \sqsubseteq w_{0}\right.\right.$, $s_{2} \sqsubseteq w_{0},\left[s_{3}, y \mid\right.$ TAKE_BRIBES $\left.\left.\left(s_{3}, y\right)\right] \Rightarrow\left[\mid \operatorname{CORRUPT}\left(s_{3}, y\right)\right]\right] \Rightarrow$ $\left.\left[s_{5} \mid \operatorname{CORRUPT}\left(s_{5}, x\right), s_{5} \sqsubseteq w_{0}\right]\right]$

(61) a. If John is a judge, then it is not the case that John as a judge both is and is not corrupt

b. $\left[x \mid \operatorname{JOHN}(x),\left[s_{1} \mid \operatorname{JUdGE}\left(s_{1}, x\right), s_{1} \sqsubseteq w_{1} /\left\{\left[\mid w_{1} \in W S\right],\left[w_{1} \mid\right]\right\}\right] \Rightarrow\right.$

$\llbracket \neg\left[s_{3} \mid \operatorname{CORRUPT}\left(s_{3}, x\right), s_{3} \sqsubseteq w_{2}, \neg\left[s_{4} \mid \operatorname{CORRUPT}\left(s_{4}, x\right), s_{4} \sqsubseteq w_{3} /\right.\right.$ $\left.\left.\left.\left.\left\{\left[\mid w_{3} \in W S\right],\left[w_{3} \mid\right]\right\}\right] /\left\{\left[\mid \operatorname{JudgE}\left(s_{2}, x\right)\right],\left[s_{2} \mid\right],\left[\mid w_{2} \in W S\right],\left[w_{2} \mid\right]\right\}\right]\right]\right]$ 
c. $\begin{aligned} & {\left[w_{0}, x \mid w_{0} \in W S, \operatorname{JOHN}(x),\left[s_{1} \mid \operatorname{JUdGE}\left(s_{1}, x\right), s_{1} \sqsubseteq w_{0}\right] \Rightarrow\right.} \\ & {\left.\left[\mid \neg\left[s_{3} \mid \operatorname{CORRUPT}\left(s_{3}, x\right), s_{3} \sqsubseteq w_{0}, \neg\left[s_{4} \mid \operatorname{CORRUPT}\left(s_{4}, x\right), s_{4} \sqsubseteq w_{0}\right]\right]\right]\right] }\end{aligned}$

(62) a. If John is a judge, John as a judge either takes or does not take bribes

b. $\left[x \mid \operatorname{JOHN}(x),\left[s_{1} \mid \operatorname{JUdGE}\left(s_{1}, x\right), s_{1} \sqsubseteq w_{1} /\left\{\left[\mid w_{1} \in W S\right],\left[w_{1} \mid\right]\right\}\right] \Rightarrow\right.$ $\left[\mid\left[s_{3} \mid\right.\right.$ TAKE_BRIBES $\left.\left(s_{3}, x\right), s_{3} \sqsubseteq w_{2} /\left\{\left[\mid w_{2} \in W S\right],\left[w_{2} \mid\right]\right\}\right] \vee$ $\left[\mid \neg\left[s_{4} \mid\right.\right.$ TAKE_BRIBES $\left(s_{4}, x\right), s_{4} \sqsubseteq w_{3} /$ $\left.\left.\left.\left.\left\{\left[\mid w_{3} \in W S\right],\left[w_{3} \mid\right]\right\}\right]\right] /\left\{\left[\mid \operatorname{JUdGE}\left(x, s_{2}\right)\right],\left[s_{2} \mid\right]\right\}\right]\right]$

c. $\left[w_{0}, x \mid w_{0} \in W S, \operatorname{JOHN}(x),\left[s_{1} \mid \operatorname{JUdGE}\left(s_{1}, x\right), s_{1} \sqsubseteq w_{0}\right] \Rightarrow\right.$ $\left[\mid\left[s_{3} \mid\right.\right.$ TAKE_BRIBES $\left.\left(s_{3}, x\right), s_{3} \sqsubseteq w_{0}\right] \vee\left[\mid \neg\left[s_{4} \mid\right.\right.$ TAKE_BRIBES $\left.\left.\left.\left.\left(s_{4}, x\right), s_{4} \sqsubseteq w_{0}\right]\right]\right]\right]$

(63) a. If John as a judge is corrupt, John is a judge

b. $\left[x \mid \operatorname{JOHN}(x),\left[s_{1} \mid \operatorname{CORRUPT}\left(s_{1}, x\right), s_{1} \sqsubseteq w_{1} /\right.\right.$ $\left.\left\{\left[\mid w_{1} \in W S\right],\left[w_{1} \mid\right],\left[\mid \operatorname{JUdGE}\left(s_{2}, x\right)\right],\left[s_{2} \mid\right]\right\}\right] \Rightarrow$ $\left.\left[s_{3} \mid \operatorname{JUdGE}\left(s_{3}, x\right), s_{3} \sqsubseteq w_{2}, /\left\{\left[\mid w_{2} \in W S\right],\left[w_{2} \mid\right]\right\}\right]\right]$

c. $\left[w_{0}, x \mid w_{0} \in W S, \operatorname{JOHN}(x),\left[s_{1} \mid \operatorname{CORRUPT}\left(s_{1}, x\right), s_{1} \sqsubseteq w_{0}, \operatorname{JUdGE}\left(s_{1}, x\right)\right] \Rightarrow\right.$ $\left.\left[s_{3} \mid \operatorname{JUDGE}\left(s_{3}, x\right), s_{3} \sqsubseteq w_{0},\right]\right]$

(Note that the last axiom is actually ambiguous, depending on whether $s_{2}$ is bound to $s_{1}$ or $w_{0}$. In the latter case, global accommodation of JUDGE is licit and we derive an (existing) reading where John's being a judge is entailed.)

It is easy to see that all these axioms are truth conditionally equivalent to the DRS $\left[w_{0}, x \mid w_{0} \in\right.$ $W S, \operatorname{JOHN}(x)]$. If one grants that this is valid in the model, the modified versions of Landman's axioms are in fact validated by our semantics.

\subsection{Consistency and underspecification}

The really interesting point about $a s$-headed adjuncts is the fact that they render else inconsistent statements consistent. We repeat the example Landman 1989 uses to illustrate this effect:

(64) John as a judge is corrupt, but John as a janitor is not corrupt

According to the semantics of as developed so far, this will still come out as a contradiction. However, a closer examination of the example reveals that it does not involve two contradictory properties in any way. As Bartsch 1987 points out, the as-PPs supply values for underspecified parameters of the main predicate. So (64) can be paraphrased as

(65) John is a corrupt judge, and he is a janitor, but he is not a corrupt janitor

This sentence is perfectly consistent. If Bartsch's suggestion points into the right direction, we expect that the consistency effect disappears if the main predicate is not underspecified in a way that could be resolved by the as-phrase. This is in fact borne out.

(66) John as a student was exactly 6 feet tall yesterday at noon, but as an athlete he was exactly 5 feet tall at that time

This sentence is in fact inconsistent.

So the picture that arises is the following: Contrary to what Landman suggests, the interpretation of the subject in a sentence like 
(67) John as a judge is corrupt

is entirely standard and classical; the sentence is a statement about the individual John, and this individual is absolutely consistent. There is no need for an ontology of "individuals under guises". Rather, as-phrases play a role in the process of the resolution of underspecification. The consistency effects are a pure side-effect of this. What has to be clarified is how exactly syntax, semantics and pragmatics interact to bring about this effect.

Bartsch 1987 suggests to bake the underspecification resolving function of as-phrases right into the syntax-semantics interface. Such an approach strikes me unattractive for two reasons. First, as-phrases have other functions as well, as the discussion in section 1 of this article demonstrates. Ideally, one approach should cover as many usages as possible. Second, the effect under discussion is defeasible. If the context supplies a better value for the underspecified parameter of the main predicate, the as-phrase may be turned into an ordinary presupposition. This is illustrated in (68).

(68) John is a highly creative researcher. Even as dean he was creative.

In the preferred reading, the second sentence entails that John was a creative researcher, not that he was a creative dean. Since this kind of non-monotonicity is characteristic of pragmatics rather than of the "hard-wired" syntax-semantic interface, a pragmatic approach has some initial plausibility.

To be somewhat more specific, we believe that the underspecification resolving effect of asadjuncts is just a side effect of their presuppositional nature. In other words, in the examples in question two dimensions of underspecification are involved: unresolved presuppositions and underspecified parameters originating from lexical semantics. Along both dimensions, resolution candidates are ranked by certain pragmatic preference measures. Van der Sandt's principles "Binding is better than accommodation", "Bind as low as possible", "Accommodate as high as possible" are some, but not all aspects that play a role here. Crucially, we assume that resolution candidates along both dimensions of underspecification wind up being in the same reference set. In other words, resolution candidates that differ only in the choice of a lexical parameter might be ranked differently because one requires presupposition accommodation while the other can do with presupposition binding.

How is lexical underspecification to be handled in the van der Sandt style version of DRT? We suggest that the sentence (69a) is equivalent to (69b) at some level of representation, where "P" is an underspecified parameter. Formally, we treat parameters as constants, so resolution comes down to a choice between models that map parameters to different denotations.
a. John is corrupt
b. John is a corrupt $\mathbf{P}$

However, the choice of a value for $\mathbf{P}$ is not entirely free; it has to be supplied by the context. This means that $\mathbf{P}$ is anaphoric in a sense. In van der Sandt's framework, this amounts to saying that John's being $\mathbf{P}$ is presupposed. So an adequate representation of $(69 \mathrm{a})$ would be $(70){ }^{9}$ where the third argument of the predicate CORRUPT indicates the dimension of corruption.

$$
\text { (70) }\left[w_{0}, x, s \mid w_{0} \in W S, \operatorname{JOHN}(x), \operatorname{CORRUPT}(s, x, \mathbf{P}), s \sqsubseteq w_{0} /\{[\mid \mathbf{P}(s, x)]\}\right]
$$

\footnotetext{
${ }^{9}$ For better readability, we preprocess the presuppositions concerning the eventuality argument.
} 
So we assume that the sentence presupposes John's being $\mathbf{P}$, and furthermore we assume that John's being $\mathbf{P}$ and John's being corrupt as a $\mathbf{P}$ are inseparable, i.e. they are true in the very same situation $s$. Without further contextual information, this presupposition is locally accommodated, so the final interpretation turns out to be (71), as far as sentence grammar is concerned. The value for $\mathbf{P}$ has to be supplied by extra-sentential information.

(71) $\left[w_{0}, x, s \mid w_{0} \in W S, \operatorname{JOHN}(x), \operatorname{CORRUPT}(s, x, \mathbf{P}), s \sqsubseteq w_{0}, \mathbf{P}(s, x)\right]$

Now reconsider the critical (72a), which receives the initial representation (72b).
a. John as a judge is corrupt
b. $\left[w_{0}, x, s_{1} \mid w_{0} \in W S, \operatorname{JOHN}(x), \operatorname{CORRUPT}\left(s_{1}, x, \mathbf{P}\right), s_{1} \sqsubseteq w_{0} /\right.$ $\left.\left\{\left[\mid \mathbf{P}\left(s_{1}, x\right)\right],\left[\mid \operatorname{JUdGE}\left(s_{2}, x\right)\right],\left[s_{2} \mid\right]\right\}\right]$

There is no choice but to bind the anaphor $s_{2}$ to $s_{1}$ and to accommodate the presupposition $\left[\mid \operatorname{JUDGE}\left(s_{2}, x\right)\right]$. So we arrive at the intermediate representation

(73) $\left\{w_{0}, x, s_{1} \mid w_{0} \in W S, \operatorname{JOHN}(x), \operatorname{CORRUPT}\left(s_{1}, x, \mathbf{P}\right) s_{1} \sqsubseteq w_{0}, \operatorname{JUdGE}\left(s_{1}, x\right) /\right.$ $\left.\left\{\left[\mid \mathbf{P}\left(s_{1}, x\right)\right]\right\}\right]$

Now we have to consider two options.

1. P receives some contextual value different from JUDGE. Then the remaining presupposition does not find an antecedent and is thus accommodated, yielding the representation

(74) $\left[w_{0}, x, s_{1} \mid w_{0} \in W S, \operatorname{JOHN}(x), \operatorname{CORRUPT}\left(s_{1}, x, \mathbf{P}\right), s_{1} \sqsubseteq w_{0}, \operatorname{JUdGE}\left(s_{1}, x\right)\right.$, $\left.\mathbf{P}\left(s_{1}, x\right)\right]$

2. $\mathbf{P}$ is instantiated as JUDGE. This resolution step gives us (75a). From there we can proceed to $(75 \mathrm{~b})$ via presupposition binding rather than accommodation.
a. $\left[w_{0}, x, s_{1} \mid w_{0} \in W S, \operatorname{JOHN}(x), \operatorname{CORRUPT}\left(s_{1}, x, \mathrm{JUDGE}\right), s_{1} \sqsubseteq w_{0}\right.$, $\left.\operatorname{JUdGE}\left(s_{1}, x\right) /\left\{\left[\mid \operatorname{JUdGE}\left(s_{1}, x\right)\right]\right\}\right]$
b. $\left[w_{0}, x, s_{1} \mid w_{0} \in W S, \operatorname{JOHN}(x), \operatorname{CORRUPT}\left(s_{1}, x, \operatorname{JUDGE}\right), s_{1} \sqsubseteq w_{0}\right.$, $\left.\operatorname{JUDGE}\left(s_{1}, x\right)\right]$

Crucially, the first option has to take resort to presupposition accommodation, while the second option can do with presupposition binding. Since binding is ceteris paribus preferred over accommodation, instantiating $\mathbf{P}$ with JUDGE is preferred over any other instantiation. Generally, taking the value for a presupposed underspecified parameter from another presupposition saves one accommodation step and is thus preferred. Of course this preference ordering is defeasible; if another instantiation of $\mathbf{P}$ leads to a configuration where binding is also possible (as in (68)), such a reading would not be blocked.

To sum up so far, our explanation of the consistency effects runs as follows:

- In the critical examples, the main predicate (like corrupt) is underspecified; it contains an open parameter for a property. 
- It is presupposed that this unspecified property holds of the subject.

- $A s$-adjuncts trigger a presupposition that their complement predicate holds of the subject.

- Identifying the unspecified property parameter with the content of the as-phrase leads to a configuration where accommodation is required only once; otherwise accommodation is required twice.

- The derivation with the least number of accommodation steps wins.

\subsection{Copular adjuncts}

From what we said in the previous subsection, one would expect that frame setting be-headed adjuncts behave exactly the same way. Since all frame setting adjuncts are assumed to be presuppositional, an appropriate choice of value for the lexical presupposition of the main predicate should help to avoid accommodation here as well. This is blatantly false.

(76) Being a judge, John is corrupt

Here the dimension of corruption is entirely open; the adjunct provides a reason for John's being a corrupt $\mathbf{P}$, but it does not supply a value for $\mathbf{P}$.

Let us see what the formal theory predicts. Putting the pieces from this and the last section together, we arrive at the initial representation (77) for (76). Note that now the situation argument of judge, $s_{2}$ is existentially bound by the copula, and an additional world size argument is introduced.

(77) $\left[w_{0}, x, s_{1} \mid w_{0} \in W S, \operatorname{JOHN}(x), \operatorname{CORRUPT}\left(s_{1}, x, \mathbf{P}\right), s_{1} \sqsubseteq w_{0} /\right.$ $\left.\left\{\left[\mid \mathbf{P}\left(s_{1}, x\right)\right],\left[s_{2} \mid \operatorname{JudGE}\left(s_{2}, x\right), s_{2} \sqsubseteq w_{1}, /\left\{w_{1} \in W S\right\}\right],\left[w_{1} \mid\right]\right\}\right]$

The next three resolution steps are fully deterministic; first we bind $w_{1}$ to $w_{0}$, second we bind the sortal restriction $\left[\mid w_{0} \in W S\right]$, and finally we accommodate the remaining presupposition that originates from the adjunct.

$$
\begin{aligned}
& \text { a. }\left[w_{0}, x, s_{1} \mid w_{0} \in W S, \operatorname{JOHN}(x), \operatorname{CORRUPT}\left(s_{1}, x, \mathbf{P}\right), s_{1} \sqsubseteq w_{0} /\right. \\
& \left.\left\{\left[\mid \mathbf{P}\left(s_{1}, x\right)\right],\left[s_{2} \mid \operatorname{JUdGE}\left(s_{2}, x\right), s_{2} \sqsubseteq w_{1}, /\left\{w_{1} \in W S\right\}\right],\left[w_{1} \mid\right]\right\}\right] \\
& \text { b. }\left[w_{0}, x, s_{1} \mid w_{0} \in W S, \operatorname{JOHN}(x), \operatorname{CORRUPT}\left(s_{1}, x, \mathbf{P}\right), s_{1} \sqsubseteq w_{0} /\right. \\
& \left.\left\{\left[\mid \mathbf{P}\left(s_{1}, x\right)\right],\left[s_{2} \mid \operatorname{JUdGE}\left(s_{2}, x\right), s_{2} \sqsubseteq w_{0}, /\left\{w_{0} \in W S\right\}\right]\right\}\right] \\
& \text { c. }\left[w_{0}, x, s_{1} \mid w_{0} \in W S, \operatorname{JOHN}(x), \operatorname{CORRUPT}\left(s_{1}, x, \mathbf{P}\right), s_{1} \sqsubseteq w_{0} /\right. \\
& \left.\left\{\left[\mid \mathbf{P}\left(s_{1}, x\right)\right],\left[s_{2} \mid \operatorname{JudGE}\left(s_{2}, x\right), s_{2} \sqsubseteq w_{0}\right]\right\}\right] \\
& \text { d. }\left[w_{0}, x, s_{1}, s_{2} \mid w_{0} \in W S, \operatorname{JOHN}(x), \operatorname{CORRUPT}\left(s_{1}, x, \mathbf{P}\right), s_{1} \sqsubseteq w_{0}, \operatorname{JUdGE}\left(s_{2}, x\right)\right. \text {, } \\
& \left.s_{2} \sqsubseteq w_{0} /\left\{\left[\mid \mathbf{P}\left(s_{1}, x\right)\right]\right\}\right\}
\end{aligned}
$$

Note that now, JUDGE and $\mathbf{P}$ have different situational arguments. So the remaining presupposition has to be accommodated, no matter which value we choose for $\mathbf{P}$. We always end up with the structure

(79) $\left[w_{0}, x, s_{1}, s_{2} \mid w_{0} \in W S, \operatorname{JOHN}(x), \operatorname{CORRUPT}\left(s_{1}, x, \mathbf{P}\right), s_{1} \sqsubseteq w_{0}, \operatorname{JUdGE}\left(s_{2}, x\right)\right.$, $\left.s_{2} \sqsubseteq w_{0}, \mathbf{P}\left(s_{1}, x\right)\right]$ 
So with copular free adjuncts, every value for $\mathbf{P}$ gives rise to the same number of accommodations, and thus sentence grammar gives no clue how this underspecification is to be resolved.

It should be noted though that the intuitive interpretation of (76) is somewhat stronger than what (79) expresses; it can be paraphrased as Because John is a judge, he is corrupt. The missing piece of meaning is arguably not supplied by sentence grammar, however. First note that minimal changes in the construction change the choice of the relation holding between John's being a judge and his being corrupt:

Despite being a judge, John is corrupt

We believe that the interpretative mechanisms involved here are analogous to the discourse interpretation principles at the discourse level that are investigated a.o. in Asher 1993. Since sentence grammar supplies descriptions of two unrelated situations in (79), the discourse module supplies a rhetorical relation like "reason" that connects these situations, to make the discourse coherent. This issue deserves further investigation, but it is largely independent of the problems discussed in this paper, therefore we do not discuss it any further here.

To summarize the discussion in this section, free adjuncts may supply a value for underspecified parameters of the main predicate due to their presuppositional character. Information flow between adjunct and main predicate is provided by the presupposition resolution module. However, this information flow is situated. Only information about the same situation may be shared between different presuppositions. Copular adjuncts come with their own situation; thus information flow is blocked there.

\section{Weak and strong adjuncts}

As mentioned in the introduction, Stump 1985 noted that some but not all free adjuncts may be interpreted as part of the restrictor of some superordinate functor. One of Stump's minimal pairs is:
a. Being a sailor, John sometimes smokes a pipe
b. Lying on the beach, John sometimes smokes a pipe

While ( $81 \mathrm{~b})$ may be interpreted as Sometimes when he is lying on the beach..., no such interpretation is possible in (81a). Here the adjunct is interpreted factively and linked to the main predication via the discourse relation "reason" as in the examples discussed in the previous section. (Though less preferred, an analogous reading is possible for (81b) too. Crucially, (a) has only this reading.) In Stump's terminology, a free adjunct is "strong" if and only if it only admits a factive interpretation in such a construction. Adjuncts that allow a restrictive interpretation are called "weak". It should be noted that the distinction between weak and strong adjuncts is stable across all kinds of binary operators. Adverbs of quantification, the implicit generic operator, modal operators etc. induce exactly the same categorization.

This distinction is relevant for our topic because as-adjuncts are always weak while copular adjuncts are generally strong. In the sequel it will be demonstrated that this contrast is in fact predicted under the assumptions made above without further stipulations.

Consider the following example

(82) As a tourist, John always smokes 
Following standard practice, I assume that an adverb of quantification like always (a) creates a duplex condition where the rest of the clause ends up in the nuclear scope, and (b) it binds the situation argument of the modified sentence (rather than a temporal argument, $\mathrm{cf}$. Lewis 1975). Formally, the lexical entry of always thus is

(83) $\lambda P \lambda w \cdot[\mid \operatorname{AlwaYs}([s \mid s \sqsubseteq w],[\mid P(s)]) /\{[\mid w \in W S\}\}]$

So the initial representation of (82) comes out as

(84) $\left[w_{0}, x \mid w_{0} \in W S, \operatorname{JOHN}(x), \operatorname{ALWAYS}\left(\left[s_{1} \mid s_{1} \sqsubseteq w_{0}\right],\left[\mid \operatorname{SMOKE}\left(s_{1}, x\right) /\right.\right.\right.$ $\left.\left.\left.\left\{\left[\mid \operatorname{TOURIST}\left(s_{2}, x\right)\right\},\left[s_{2} \mid\right]\right\}\right]\right)\right\}$

In the next resolution step, the situation anaphor $s_{2}$ has to be bound. Binding takes place as low a possible, so $s_{1}$ in the restrictor is the preferred binder. So the intermediate representation is

(85) $\left[w_{0}, x \mid w_{0} \in W S, \operatorname{JOHN}(x), \operatorname{ALWAYS}\left(\left[s_{1} \mid s_{1} \sqsubseteq w_{0}\right],\left[\mid \operatorname{SMOKE}\left(s_{1}, x\right) /\right.\right.\right.$ $\left.\left.\left.\left\{\left[\mid \operatorname{TOURIST}\left(s_{1}, x\right)\right]\right\}\right\}\right)\right]$

There is no antecedent for the remaining presupposition; it has to be accommodated. The accommodation site should be as high as possible provided no bound discourse markers become unbound. Here the discourse marker $s_{1}$ is bound in the restrictor, thus global accommodation is blocked. Intermediate accommodation is the preferred option, i.e.

$$
\left[w_{0}, x \mid w_{0} \in W S, \operatorname{JOHN}(x), \operatorname{ALWAYS}\left(\left[s_{1} \mid s_{1} \sqsubseteq w_{0}, \operatorname{TOURIST}\left(s_{1}, x\right)\right],\left[\mid \operatorname{SMOKE}\left(s_{1}, x\right)\right]\right)\right]
$$

Note that there is also a less preferred option for global accommodation if we bind $s_{2}$ to $w_{0}$.

Now let us compare this with the strong construction

(87) Being a tourist, John always smokes

The initial representation is as above, apart from the fact that the copula binds the situation variable of tourist and replaces it by a world variable.

$$
\begin{aligned}
& {\left[w_{0}, x \mid w_{0} \in W S, \operatorname{joHn}(x), \operatorname{ALways}\left(\left[s_{1} \mid s_{1} \sqsubseteq w_{0}\right\},\left[\mid \operatorname{smoke}\left(s_{1}, x\right) /\right.\right.\right.} \\
& \left.\left.\left.\left\{\left\{s_{2} \mid s_{2} \sqsubseteq w_{1}, \operatorname{TOURist}\left(s_{2}, x\right) /\left\{w_{1} \in W S\right\}\right],\left[w_{1} \mid\right]\right]\right\}\right)\right]
\end{aligned}
$$

The world anaphor $w_{1}$ is preferably bound to the situation $s_{1}$. However, this would enforce intermediate accommodation of the sortal information $w_{1} \in W S$. Binding $w_{1}$ to $w_{0}, w_{1} \in W S$ need not be accommodated at all but can be bound at the global level. We take it that the constraint "Avoid Accommodation!" is stronger than the requirement "Bind as low as possible!", thus binding of $w_{1}$ to $s_{1}$ is blocked. ${ }^{10}$ (In analogy to pronominal anaphora one might furthermore assume that accommodation of sortal information is impossible anyway, which would also block this binding.) So the only option for resolution of $w_{1}$ is high binding, which leads to

(89) $\left[w_{0}, x \mid w_{0} \in W S, \operatorname{JOHN}(x), \operatorname{ALWAys}\left(\left[s_{1} \mid s_{1} \sqsubseteq w_{0}\right],\left[\left\{\operatorname{Smoke}\left(s_{1}, x\right) /\right.\right.\right.\right.$ $\left.\left.\left.\left\{\left[s_{2} \mid s_{2} \sqsubseteq w_{0}, \operatorname{TOURIST}\left(s_{2}, x\right)\right]\right\}\right]\right)\right]$

\footnotetext{
${ }^{10} \mathrm{~A}$ formalization in the framework of Optimality Theory suggests itself; see Blutner 1999 for a discussion of the optimality theoretic aspects of presupposition resolution.
} 
Again the remaining presupposition must be accommodated, but this time nothing blocks global accommodation, so the final representation is the strong

(90) $\left[w_{0}, x, s_{2} \mid w_{0} \in W S, s_{2} \sqsubseteq w_{0}, \operatorname{TOURIST}\left(s_{2}, x\right), \operatorname{JOHN}(x)\right.$, $\left.\operatorname{ALWAYS}\left(\left[s_{1} \mid s_{1} \sqsubseteq w_{0}\right],\left[\mid \operatorname{SMOKE}\left(s_{1}, x\right)\right]\right)\right]$

To formulate the underlying idea on a somewhat coarser level, our explanation for the weak/ strong contrast between $a s$ and be runs as follows:

- Binary operators like adverbs of quantification quantify over situations.

- $A s$-adjuncts supply a situation argument that can either be bound by the operator or be identified with the evaluation index.

- Be-adjuncts supply a world argument that cannot be bound by the operator but has to be identified with the evaluation index.

- The presupposition of the nuclear scope is accommodated to wherever its eventuality argument is bound. This is either the restrictor of the operator or the matrix context for as-adjuncts, but always the matrix context for be-adjuncts.

We conclude this section by pointing out two interesting consequences of the theory sketched here.

According to Stump, weak adjuncts are interpreted as part of the restrictor. So (91a) should be equivalent to $(91 b)$.

a. As a judge, John is always corrupt

b. When John is a judge, he is always corrupt

Sharvit (p.c.) notes that this equivalence is not complete. A more adequate paraphrase of (91a) is (92).

(92) When John is a judge, he is always a corrupt judge

So the $a s$-adjunct in (91) serves two purposes: it restricts the adverbial operator, and it supplies a value for the underspecified dimension of corruption. This is exactly what our theory predicts: (91a) receives the initial underspecified DRS (93a), which is transformed to (b) or (c), depending on whether $\mathbf{P}$ is or is not instantiated by JUDGE. Since the former admits binding while the latter requires accommodation, (b) represents the preferred reading, which is equivalent to (92).
a. $\lambda w_{1} \cdot\left[x \mid w_{1} \in W S, \operatorname{JOHN}(x), \operatorname{ALWAYS}\left(\left[s_{1} \mid s_{1} \sqsubseteq w_{2}\right],\left[\mid \operatorname{CORRUPT}\left(s_{1}, x, \mathbf{P}\right) /\right.\right.\right.$ $\left.\left.\left.\left\{\left[\mid w_{2} \in W S\right],\left[w_{2} \mid\right],\left[\mid \mathbf{P}\left(s_{1}, x\right)\right],\left[\mid \operatorname{JUdGE}\left(s_{2}, x\right)\right],\left\{s_{2} \mid\right]\right\}\right]\right)\right]$
b. $\left[w_{0}, x \mid w_{0} \in W S, \operatorname{JOHN}(x), \operatorname{ALWAYS}\left(\left[s_{1} \mid s_{1} \sqsubseteq w_{0}, \operatorname{JUdGE}\left(s_{1}, x\right)\right]\right.\right.$, [/CORRUPT $\left(s_{1}, x\right.$, JUDGE $\left.\left.\left.)\right]\right)\right]$
c. $\left[w_{0}, x \mid w_{0} \in W S, \operatorname{JOHN}(x), \operatorname{ALWAYs}\left\langle\left[s_{1} \mid s_{1} \sqsubseteq w_{0}, \mathbf{P}\left(s_{1}, x\right), \operatorname{JUdGE}\left(s_{1}, x\right)\right]\right.\right.$, [|CORRupt $\left.\left.\left.\left(s_{1}, x, \mathbf{P}\right)\right]\right)\right]$ 
Finally, the mechanisms involved in the interpretation of as-adjuncts that are proposed here are in no way particular for this preposition. All observed effects are derived from general properties of presupposition resolution. So we expect other presupposition triggers to lead to similar effects. Arguably, appositives like the judge in the following example triggers the presupposition that John is a judge (see for instance Lasersohn 1987; Umbach 1996 for proposals in this direction).

(94) John the judge entered

So we expect the appositive NP to behave similarly to a weak free adjunct. This is in fact what we observe.
a. John the judge always falls asleep
b. John the judge is corrupt

Sentence (95a) can be paraphrased as Always when John is a judge, he falls asleep in one of its readings, and (95b) can be interpreted as equivalent to John is a corrupt judge. So neither the interaction with operators nor the interaction with underspecified predicates is an idiosyncrasy of as-adjuncts. Rather, both can be derived from their presuppositional nature.

\section{Conclusion and further research}

Let us briefly summarize our findings. We started the discussion with the fact noted by Stump that as-PPs are admitted in the complement of verbs of perception while copular predicates are excluded there. Stump analyzed this fact in a Carlsonian fashion by classifying as-PPs as SLPs and copular predicates as ILPs.

We argued that the Carlsonian approach to the semantics of verbs of perception is insufficient for independent reasons. We proposed a modification that maintains some of Carlson's intuitive approach. We agree with Carlson that perception involves partial objects, and thus predicates ranging over total objects are excluded in the complement of see. However, we shift the partial/total contrast from the domain of individuals to the domain of eventualities. To this end we employed a Kratzer style ontology where abstract objects may be classified as possible situations or possible worlds. The contrasts between $a s$ and $b e$ was explained by the assumption that as-PPs denote properties that have a situation argument (inherited from the NP complement), while the copula induces a sortal shift from situations in general to possible worlds. Therefore copular predicates are excluded in perception constructions.

Next we turned attention to free adjuncts. Following suggestions from Maienborn, we analyze free adjuncts as frame setting, i.e. topical adverbials. As such they are presuppositional. We embedded this idea into the overall semantic/pragmatic framework by van der Sandt. There presupposition resolution is considered a non-deterministic transformation over discourse representations. The possible outcomes are evaluated according to several criteria. The principle "Presupposition binding is better than presupposition accommodation" turned out to be crucial for the analysis of the phenomena under investigation. As-adjuncts may supply a value for underspecified aspects of the meaning of the main predicate because this parameter setting saves one accommodation step. This only works if the main predicate and the free adjunct share a situation argument. Therefore this effect is not observed with copular free adjuncts; the copula introduces its own situation argument, thus information flow between the predicates is blocked.

Finally we demonstrated that the weak/strong contrast between as-adjuncts and be-adjuncts falls out from these assumption without further ado. The situation argument of an as-adjunct 
may be bound by an adverb of quantification or a similar operator. The world argument of a $b e$-adjunct can only be identified with the index of evaluation. Since in van der Sandt's model presuppositions are always accommodated as high as possible, as-adjuncts prefer intermediate accommodation, i.e. a weak construal, while copular adjuncts must be interpreted strong, this means via global accommodation.

Let us conclude with pointing out some possible continuations of this line of research. As I argued elsewhere (Jäger 1999), Carlson overgeneralizes in subsuming several contrasts under the heading "SLP/ILP" that are better kept apart. However, if the basic idea laid down here is right, the contrasts observed in the complement of perceptual reports, Stump's weak/strong distinction, and Maienborn's distinction between stative and non-stative predicates should coincide. It remains to be seen whether this is borne out.

Stump points out that the main verb have behaves similar to be. In his terminology, VPs headed by have are always ILP. And like be, have has a SLP-creating counterpart, namely the preposition with. He gives the following minimal pair:

a. Having green eyes, Mary might look something like Jane

b. With green eyes, Mary might look something like Jane

Only (96b) admits a weak construal, (a) is unequivocally strong. Ideally, this contrast should be explicable solely in terms of worlds vs. situations, as in the case of as and be.

We restricted attention to frame setting adverbials here. As-PPs occur in other syntactic configurations as well, as the following examples may illustrate.
a. John works as a judge
b. John acted as a judge
c. John was disguised as a judge

If our situation based approach to the semantics of as is correct, it should provide insights into the semantics of these and related constructions as well.

Last but not least, cross-linguistic investigations are called for. Several languages (Celtic languages, Hebrew, Spanish etc.) have more than one copula. Do they behave uniformly with respect to the world/situation contrast? If not, what consequences are predicted, and are these predictions confirmed? As for as, how do its cross-linguistic counterparts behave? Russian seems to be a particularly interesting case here, since instrumental case-which corresponds to English as in many contexts-may occur in copular constructions (cf. Geist 1998; Partee 1998). So here we can observe a direct interaction between the two modes of predication that were treated as complementary in this paper. 


\section{References}

Asher, Nicholas (1993): Reference to Abstract Objects in Discourse, Kluwer, Dordrecht.

Bartsch, Renate (1987): Context-dependent Interpretations of Lexical Items, in: Jeroen Groenendijk, Dick de Jong and Martin Stokhof (eds.), Foundations of Pragmatics and Lexical Semantics, 1-25, Foris, Dordrecht.

Barwise, Jon (1981): Scenes and Other Situations, Journal of Philosphy 78, 369-397.

Blutner, Reinhard (1999): Some Aspects of Optimality in Natural Language Interpretation, ms., Berlin.

Bowers, John (1993): The Syntax of Predication, Linguistic Inquiry 24, 591-656.

Carlson, Gregory N. (1977): Reference to Kinds in English, Ph.D. thesis, University of Massachusetts, Amherst.

Davidson, Donald (1967): The Logical Form of Action Sentences, in: Nicolas Rescher (ed.), The Logic of Decision and Action, 81-95, University of Pittsburgh Press.

- (1969): The Individuation of Events, in: Nicolas Rescher (ed.), Essays in Honor of Carl G. Hempel, 216-234, Reidel, Dordrecht.

Dekker, Paul (1990): Existential Disclosure, Technical report, ILLC, University of Amsterdam.

Diesing, Molly (1992): Indefinites, MIT Press, Cambridge (Mass.).

Fernald, Theodore B. (2000): Predicates and Temporal Arguments, Oxford University Press, Oxford.

Fox, Chris (1993): Individuals and Their Guises: a Property-theoretic Analysis, in: Paul Dekker and Martin Stokhof (eds.), Proceedings of the Ninth Amsterdam Colloquium, volume II, 301-312, University of Amsterdam.

Gawron, Jean Mark and Stanley Peters (1990): Anaphora and Quantification in Situation Semantics, CSLI, Stanford.

Geist, Ljudmila (1998): Kopulaverben und Prädikativkonstruktionen: ein deutsch-russischer Vergleich, Master's thesis, Humboldt-Universität zu Berlin.

Higginbotham, James (1983): The Logic of Perceptual Reports: An Extensional Alternative to Situation Semantics, The Journal of Philosophy 80, 100-127.

Jäger, Gerhard (1999): Stage levels, states, and the semantics of the copula, in: Ewald Lang and Ljudmila Geist (eds.), Kopula-Prädikativ-Konstruktionen als Syntax-Semantik-Schnittstelle, ZAS Papers in Linguistics 14, 65-94, ZAS, Berlin.

Kamp, Hans (1981): A Theory of Truth and Semantic Representation, in: Jeroen Groenendijk, Theo Janssen and Martin Stokhof (eds.), Formal Methods in the Study of Language, 277-322, Amsterdam.

Kamp, Hans and Uwe Reyle (1993): From Discourse to Logic. Introduction to Modeltheoretic Semantics of Natural Language, Formal Logic and Discourse Representation Theory, Kluwer, Dordrecht.

Katz, Graham (1994): The interpretation of as-headed Adjuncts, in: Erin Duncan, Donka Farkas and Philip Spaelti (eds.), Proceedings of WCCFL 12, 547-560, CSLI, Stanford.

Kratzer, Angelika (1989): An Investigation of the Lumps of Thought, Linguistics and Philosophy 12, 607-653.

- (1995): Stage-level and Individual-level Predicates, in: Gregory N. Carlson and Francis J. Pelletier (eds.), The Generic Book, 125-175, University of Chicago Press.

Krifka, Manfred, Francis J. Pelletier, Gregory N. Carlson, Alice ter Meulen, Gennaro Chierchia and Godehard Link (1995): Genericity: An Introduction, in: Gregory N. Carlson and Francis J. Pelletier (eds.), The Generic Book, 1-124, University of Chicago Press.

Landman, Fred (1989): Groups II, Linguistics and Philosophy 12, 723-744.

Lasersohn, Peter (1987): The Semantics of Appositive and Pseudo-Appositive NPs, in: Fred Marshall, Ann Miller and Zheng-sheng Zhang (eds.), ESCOL 86: Proceedings of the Third Eastern States Conference on Linguistics, 311-322, Ohio State University.

Lewis, David (1975): Adverbs of Quantification, in: Edward L. Keenan (ed.), Formal Semantics, 3-15, Cambridge University Press.

Maienborn, Claudia (1999a): Kopula-Prädikativ-Konstruktionen, draft, Humboldt University Berlin.

- (1999b): Situationsbezug und die Stadien/Individuen-Distinktion bei Kopula-Prädikativ-Konstruktionen, in: Ewald Lang and Ljudmila Geist (eds.), Kopula-Prädikativkonstruktionen als Syntax-Semantik-Schnittstelle, (= ZAS Papers in Linguistics 14), 41-64, Zentrum für Allgemeine Sprachwissenschaft, Berlin.

Partee, Barbara (1986): Ambiguous Pseudoclefts with Unambiguous Be, in: Steve Berman, J. Choe and J. McDonough (eds.), Proceedings of NELS 16, 354-366, GLSA, Amherst.

- (1998): Copula Inversion Puzzles in English and Russian, paper presented at FASL 7, Seattle

Stump, Gregory T. (1985): The Semantic Variablity of Absolute Constructions, Reidel, Dordrecht. 


\section{Gerhard Jäger}

Lmbach, Carla (1996): Termpräzisierung: Kontextuelle Steuerung der Interpretation durch Apposition und Typisierung, Ph.D. thesis, Technical University of Berlin.

van der Sandt, Rob (1992): Presupposition projection as anaphora resolution, Journal of Semantics 9, 333-377.

von Fintel, Kai (1994): Restrictions on Quantifier Domains, Ph.D. thesis, University of Massachusetts, Amherst (Mass.).

Zeevat, Henk (1989): A Compositional Approach to Discourse Representation Theory, Linguistics and Philosophy 12, 95-131.

- (1992): Presupposition and Accommodation in Update Semantics, Journal of Semantics 9, 379-412. 


\section{Appendix: Compositional DRT}

Syntax The language of compositional DRT used in this paper is basically an extension of standard DRT syntax with $\lambda$-abstraction. Every well-formed expression has a type, where types are formed from the basic types $t$ (update) and $e$ (entity) by means of function space formation in the standard Montagovian fashion. There are infinitely many variables and constants of each type. Furthermore there is a distinguished infinite set $D M$ of constants of type $e$, the discourse markers. We use boldface lowercase Latin letters as meta-variables for discourse markers. The syntax is defined by the following rules:

\section{Definition 1 (Syntax of Compositional DRT)}

1. All variables and constants are expressions of their respective type.

2. If $\varphi$ has type $\langle A, B\rangle$ and $\psi$ has type $A$, then $\varphi(\psi)$ has type $B$.

3. If $v$ is a variable of type $A$ and $\varphi$ has type $B$, then $\lambda v \cdot \varphi$ has type $\langle A, B\rangle$.

4. If both $\varphi$ and $\psi$ have type $A$, then $\varphi=\psi$ has type $t$.

5. If $\mathbf{x}_{1} \cdots \mathbf{x}_{n}$ are discourse markers and $\varphi_{1} \cdots \varphi_{m}$ have type $t$, then $\left[\mathbf{x}_{1} \cdots \mathbf{x}_{n} \mid \varphi_{1}, \cdots, \varphi_{m}\right]$, $\neg \varphi_{1}$ have type $t$.

Semantics A model $M=\langle\mathcal{K}, \Sigma, F\rangle$ consists of a Kratzer frame $\mathcal{K}$ in the sense defined in the text (a set of individuals $A$, a set of situations $S$, an ordering of situations etc.), a state space $\Sigma$, i.e. a set of partial functions from $D M$ into the universe (with the empty function as a distinguished member), and a function $F$ that sends all non-logical constants except the discourse markers to a denotation of the appropriate type. Denotation domains of the types are defined recursively as follows:

\section{Definition 2 (Domains)}

1. $D(e)=A \cup S$

2. $D(t)=\{\langle\sigma, \tau\rangle \in \Sigma \times \Sigma \mid \sigma \subseteq \tau\}$

3. $D(\langle A, B\rangle)=D(B)^{\left(D(A)^{\Sigma}\right)}$

Furthermore interpretation depends on a set $G$ of assignment function that maps variables to functions from states to denotations of the appropriate type. The recursive interpretation function is defined as follows, where meaning assignment is always relative to a model (that is suppressed in the notation), a state $\sigma$ and an assignment function $g$. We need a 2-place merge operation $\otimes$ on states as auxiliary notion, where $(\sigma \otimes \tau)(\mathbf{x})=\sigma(\mathbf{x})$ if defined, else $\tau(\mathbf{x})$ if defined, undefined else. $\sigma \Xi_{\mathbf{x}_{1}, \cdots, \mathbf{x}_{i}} \tau$ means that $\operatorname{Domain}(\tau) \backslash \operatorname{Domain}(\sigma)=\left\{\mathbf{x}_{1}, \cdots, \mathbf{x}_{i}\right\}$ and $\sigma \subseteq \tau$. 


\section{Definition 3 (Interpretation)}

1. If $v$ is a variable, $\|v\|_{g}^{\sigma}=g(v)(\sigma)$.

2. If $\mathbf{x}$ is a discourse marker, $\|\mathbf{x}\|_{g}^{\sigma}=\sigma(\mathbf{x})$.

3. If $c$ is a constant, $\|c\|_{g}^{\sigma}=F(c)$.

4. $\|\varphi(\psi)\|_{g}^{\sigma}=\|\varphi\|_{g}^{\sigma}\left(\lambda \tau\|\psi\|_{g}^{\tau}\right)$

5. $\left\|\lambda v_{A} \varphi\right\|_{g}^{\sigma}=\left\{\left\langle\alpha,\|\varphi\|_{g[v \rightarrow \alpha]}^{\sigma}\right\rangle \mid \alpha \in D(A)^{\Sigma}\right\}$

6. $\|\varphi=\psi\|_{g}^{\sigma}=\left\{\langle\tau, \tau\rangle \in \Sigma \times \Sigma \mid\|\varphi\|_{g}^{\tau \otimes \sigma}=\|\psi\|_{g}^{\tau \otimes \sigma}\right\}$

7. $\left\|\left[\mathbf{x}_{1} \cdots \mathbf{x}_{n} \mid \varphi_{1} \cdots \varphi_{m}\right]\right\|_{g}^{\sigma}=$

$$
\left\{\left\langle\tau_{1}, \tau_{2}\right\rangle \in \Sigma \times \Sigma \mid \exists \tau_{3}\left(\tau_{1} \sqsubseteq \mathbf{x}_{1} \cdots \mathbf{x}_{n} \tau_{3} \wedge \tau_{3}\left\|\varphi_{1}\right\|_{g}^{\sigma} \circ \cdots \circ\left\|\varphi_{m}\right\|_{g}^{\sigma} \tau_{2}\right)\right\}
$$

8. $\|\neg \varphi\|_{g}^{\sigma}=\left\{\langle\tau, \tau\rangle \mid \nexists \tau_{2}: \tau\|\varphi\|_{g}^{\sigma} \tau_{2}\right\}$

As the reader may convince herself, $\alpha \beta \eta$-equivalences are meaning preserving under the usual restrictions. Furthermore, in the text we sometimes make tacit use of the conversion from

$$
\left[\mathbf{x}_{1} \cdots \mathbf{x}_{n} \mid \varphi_{1}, \cdots, \varphi_{k},\left[\mathbf{x}_{n+1} \cdots \mathbf{x}_{n+l} \mid \psi_{1}, \cdots, \psi_{m}\right], \zeta_{1}, \cdots, \zeta_{o}\right]
$$

to

$$
\left[\mathbf{x}_{1} \cdots \mathbf{x}_{n+l} \mid \varphi_{1}, \cdots, \varphi_{k}, \psi_{1}, \cdots, \psi_{m}, \zeta_{1}, \cdots, \zeta_{o}\right]
$$

This transformation is also meaning preserving provided the discourse markers $\mathbf{x}_{n+1} \cdots \mathbf{x}_{n+l}$ do not occur in any $\varphi_{i}$.

A DRS $\varphi$ is true iff there is a state $\sigma$ such that for any assignment function $g: \emptyset\|\varphi\|_{g}^{\emptyset} \sigma$.

A final remark on the intended interpretation of the non-logical constants used in the text. While intuitively a predicate constant like WALK of type $\langle e,\langle e, t\rangle\rangle$ is supposed to denote the relation between individuals $x$ and situations $s$ that holds exactly iff $x$ walks in $s$, its denotation in the formal system sketched above is a 3-place function from a state and two individual concepts (i.e. functions from states to individuals) to an update. However, the relation between the intuitive and the formal denotation is a simple implicit type lift; for the example WALK this means: $\tau \|$ WALK $\|_{g}^{\sigma}(a)(b) \tau^{\prime}$ iff $\tau=\tau^{\prime}$ and the individual $a(\tau \otimes \sigma)$ walks in the situation $b(\tau \otimes \sigma)$. The interpretation of the other predicate constants used in the text is derived from their intuitive extension in an analogous way. 